Wright State University

CORE Scholar

Mechanical and Materials Engineering Faculty

Publications

Mechanical and Materials Engineering

\title{
$5-2011$
}

\section{Synthesis and Characteristics of Nano-Ceria Supported Bimetallic Catalysts For S-Tolerant SOFCs}

Joe Bozeman

Alexis Marruffo

Ian T. Barney

A. G. Jackson

Wright State University - Main Campus, allen.jackson@wright.edu

Sharmila M. Mukhopadhyay

Wright State University - Main Campus, sharmila.mukhopadhyay@wright.edu

See next page for additional authors

Follow this and additional works at: https://corescholar.libraries.wright.edu/mme

Part of the Materials Science and Engineering Commons, and the Mechanical Engineering Commons

\section{Repository Citation}

Bozeman, J., Marruffo, A., Barney, I. T., Jackson, A. G., Mukhopadhyay, S. M., \& Huang, H. (2011).

Synthesis and Characteristics of Nano-Ceria Supported Bimetallic Catalysts For S-Tolerant SOFCs. ESC Transactions, 35 (1), 1689-1696.

https://corescholar.libraries.wright.edu/mme/60

This Article is brought to you for free and open access by the Mechanical and Materials Engineering at CORE Scholar. It has been accepted for inclusion in Mechanical and Materials Engineering Faculty Publications by an authorized administrator of CORE Scholar. For more information, please contact library-corescholar@wright.edu. 


\section{Authors}

Joe Bozeman, Alexis Marruffo, Ian T. Barney, A. G. Jackson, Sharmila M. Mukhopadhyay, and Hong Huang

This article is available at CORE Scholar: https://corescholar.libraries.wright.edu/mme/60 


\section{Synthesis and Characteristics of Nano-Ceria Supported Bimetallic Catalysts For S-Tolerant SOFCs}

Joe Bozeman, Alexis Marruffo, lan Barney, Allen Jackson, Sharmila Mukhopadhyay and Hong Huang

ECS Trans. 2011, Volume 35, Issue 1, Pages 1689-1696.

doi: $10.1149 / 1.3570156$

Email alerting

Receive free email alerts when new articles cite this article - sign up in the service 


\title{
Synthesis and Characteristics of Nano-Ceria Supported Bimetallic Catalysts For S-Tolerant SOFCs
}

\author{
J. Bozeman, A. Marruffo, I. Barney, A. Jackson, S. Mukhopadhyay and H. Huang \\ Center for Nanoscale Multifunctional Materials, \\ Department of Mechanical and Materials Engineering \\ Wright State University, Dayton, OH 45435, USA
}

\begin{abstract}
$\mathrm{Cu}-\mathrm{Pt}$ bimetal and Pt-skin structured $\mathrm{Cu}-\mathrm{Pt}$ catalysts supported on nanocrystalline $\mathrm{CeO}_{2}$ are synthesized via the low-cost sol-gel approach followed by impregnation processing. Crystal structure, particle size, bulk and surface compositions of the catalyst are systematically characterized. The average particle size of the catalytic composites is $63 \mathrm{~mm}$. The ceria supporter has a fluorite structure, while $\mathrm{Cu}$ and $\mathrm{Pt}$ contents, not detected by XRD, may exist in amorphous phases. The Pt-skin structured nanocomposite is analyzed based on the surface elemental and bulk compositional analyses. No $\mathrm{Cu}$ is detected on the surface based on XPS analyses; however, EDX bulk compositional analyses confirm the coexistence of $\mathrm{Cu}$ and $\mathrm{Pt}$. These two kinds of catalytic composites may have potentials to serve as sulfur-resistant anode in solid oxide fuel cells.
\end{abstract}

\section{Introduction}

Although innovative hydrogen production and storage technologies have garnered much attention, they remain challenging to be harnessed towards meeting practical requirements and commercialization for hydrogen-based fuel cells (1). SOFCs, because of the high operating temperatures, have potentials to directly utilize alternative fuels, such as natural gas and biogases with no need of high-grade pre-purifying process (2-5). However, the economical low-cleaning fuels usually contain hydrogen sulfide up to hundreds of ppm level (6-13). At present, SOFCs made up of Ni/yttria stabilized zirconia (YSZ) cermet anode are susceptive to sulfur. Traces of sulfur content present in the fuel source can cause dramatic performance degradation (14-22), and the consequences are attributed to i) Absorption of $\mathrm{H}_{2} \mathrm{~S}$ on surface active sites of Ni catalyst inhibits effective catalytic functionality of $\mathrm{Ni}$ for fuel oxidation; and/or ii) Formation of nickel sulfide results in complete loss of catalytic activity and conductivity (23-26).

Recently, extensive efforts have been emphasized on metal-oxide cermet anodes towards improving sulfur tolerance of SOFCs (27-36). Sulfur could be reversibly and efficiently adsorbed on the surface of ceria and doped ceria over a wide temperature range of $350-800^{\circ} \mathrm{C}(37)$, matching the operating temperatures of SOFCs. Cu-ceria composite in place of $\mathrm{Ni} / \mathrm{YSZ}$ cermet exhibited effective catalytic activity in the presence of $\mathrm{H}_{2} \mathrm{~S}(34,35)$. Gong studied Cu-ceria as the sulfur tolerant anode material and summated that the anode surface and its electronic structure played a key role in achieving sulfur-resistance (29). The enhanced sulfur tolerance of the $\mathrm{Cu}$ catalyst was attributed to copper oxide acting as a sulfidation site $(31,33,35,36)$. Pt and $\mathrm{Pd}$ catalysts 
supported on ceria were also reported to possess effective sulfur tolerant characteristics $(30,34)$. This research is to synthesize alternative nanocomposites, e.g. Pt-Cu bimetal and Pt-skin structured Pt-Cu bimetal catalysts supported on nanocrystalline $\mathrm{CeO}_{2}$, which may potentially serve as sulfur-resistant anodes for SOFCs. Sol-gel approach in combination with the impregnation procedure was adopted. Crystal structure, particle size, bulk composition, and surface composition of the bimetallic catalyst composites were analyzed using X-ray Diffraction (XRD), Atomic Force Microscopy (AFM), Energy Dispersive X-ray Spectroscopy (EDS), and X-ray Photoelectron Spectroscopy (XPS).

\section{Experimental Aspects}

\section{Synthesis of Nano-Ceria}

A sol-gel method was applied to synthesize nanocrystalline ceria. The sol-gel variant was citrate to serve as a complexing polyfunctional hydroxy agent. In the experiment, approperiate amounts of cerium (IV) nitrate hexahydrate and citric acid monohydrate, from Sigma-Aldrich, were added to distilled water until fully dissolved. After stirred and heated at $80^{\circ} \mathrm{C}$ for 2 hours, the clear solution turned into a viscous gel. The yellow paste was then dried at $250^{\circ} \mathrm{C}$ for 1 hour, and then calcined at $600^{\circ} \mathrm{C}$ for 5 hours at a ramping rate of $10^{\circ} \mathrm{C}$ per minute.

\section{Synthesis of Catalysts Covered Nano-Ceria}

An impregnation process was adopted to acquire the catalyst-covered nano-ceria powders. Copper (II) acetate hydrate (Sigma-Aldrich) was added to distilled water resulting in a molarity of $0.025 \mathrm{M}$ solution. A $0.025 \mathrm{M}$ Pt-containing solution was prepared by mixing of concentrated nitric acid, distilled water, and platinum (II) acetylacetonate (Sigma-Aldrich). The $\mathrm{Cu}$ covered $\mathrm{CeO}_{2}$ (Cu-Ceria) was synthesized as the following: $1 \mathrm{~g}$ of nano-ceria powders was placed in $0.025 \mathrm{M} \mathrm{Cu}$ acetate solution, stirred and preserved overnight. It was then filtered, washed, and dried at $250^{\circ} \mathrm{C}$. The $\mathrm{Pt}$ covered $\mathrm{CeO}_{2}$ (Pt-Ceria) followed a similar process. The $\mathrm{CuPt}$ bimetallic catalyst supported on $\mathrm{CeO}_{2}$ (bimetal $\mathrm{CuPt}$-ceria) was synthesized via impregnating nano-ceria powder in a mixture of copper-containing solution and Pt-containing solution in one-step. The Pt-skin structured CuPt catalyst supported on $\mathrm{CeO}_{2}$ (Pt-skin CuPt-ceria) was synthesized via a two-step impregnation process. The nano-ceria powder was firstly impregnated in the copper acetate solution. After the resultant powder was washed and dried, the Cu-ceria powders was placed in the platinum acetylacetonate solution, filtered, and then dried. Figure 1 schematically illustrated the four types of catalyst covered nanoceria composites.

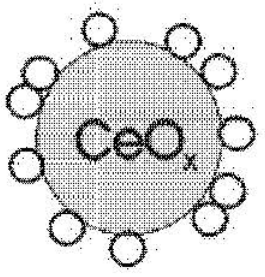

Pt-Ceria

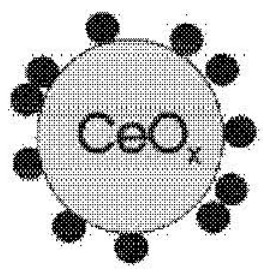

Cu-Ceria

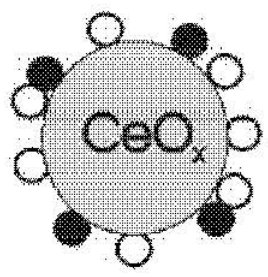

CuPt-Ceria

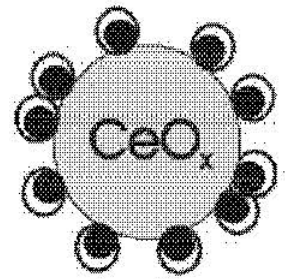

Pt-skin CuPt-Ceria

Figure 1. Schematics of the four types of catalyst covered nano-ceria composites. 


\section{Characterization of Supported Nano-Ceria Catalysts}

The bare nano-ceria and impregnated ceria specimens were subjected to a series of structural, topographical, and compositional analyses. XRD spectra were obtained on the X-ray Diffractometer (Rigaku RU200 DMAX B) in the $2 \theta$ range of $24.0^{\circ}$ to $84.0^{\circ}$ at a step rate of $2^{\circ}$ per minute. AFM topographical imaging (Agilent 5420) was used to visualize accurate particle size.

The bulk elemental compositions were analyzed by using EDS equipped in the scamning electron microscope (JEOL 7401F). Two different morphological regions and two area sizes $(10 \mu \mathrm{m}$ by $10 \mu \mathrm{m}$ and $200 \mu \mathrm{m}$ by $180 \mu \mathrm{m})$ were selected for EDS analyses. Since EDS collects elemental information of a specimen at a depth of 1-5 $\mu \mathrm{m}$, the EDS results essentially provide the average bulk composition information $(38,39)$.

X-ray Photoelectron Spectroscopy (XPS) was conducted using a Kratos Axis Ultra Instrument and analyzed with the help of CasaXPS software. All spectra were taken using mono-Al $\mathrm{K} \alpha \mathrm{X}$-rays $(1486.6 \mathrm{eV})$ and binding energies were reported as measured without correction. A series of survey scans were initially performed in the binding energy range of 1 to $1000 \mathrm{eV}$. Fine scans were subsequently administered in the pertinent binding energy ranges to elucidate content compositions and the elemental bonding state. The fine scans were focused in the ranges of $870-920 \mathrm{eV}, 930-970 \mathrm{eV}, 525-530 \mathrm{eV}$ and $70-77 \mathrm{eV}$ corresponding to $\mathrm{Cu} 2 \mathrm{p}$, Ce $3 \mathrm{~d}, \mathrm{O} 1 \mathrm{~s}$, and Pt $4 \mathrm{f}$ peaks, respectively. The XPS signals originate from the outer layers (less than 1-3 nm) of a specimen, and therefore, provides the surface-sensitive information on composition and chemistry $(38,39)$.

\section{Results and Discussion}

In order to identify the surface composition and valence states of the catalytic elements, XPS survey scans were performed in the binding energy range of $1 \mathrm{eV}$ to 1000 $\mathrm{eV}$. No impurity elements other than $\mathrm{Cu}$ and/or $\mathrm{Pt}, \mathrm{Ce}, \mathrm{O}$ were detected in the survey spectra of the impregnated specimens. Afterwards, fine scans in the interesting region were analyzed in great detail. Figure 2 displays the $\mathrm{Cu} 2 \mathrm{p}$ and $\mathrm{Pt} 4 \mathrm{f}$ XPS fine-scan spectra of the four coated specimens, i.e. Cu-ceria, Pt-ceria, bimetal CuPt-ceria, and Pt-skin $\mathrm{CuPt}$-ceria. Both $\mathrm{Pt}$ and $\mathrm{Cu}$ peaks are observable in the bimetal $\mathrm{PtCu}-\mathrm{ceria}$. However, in the $\mathrm{Pt} 4 \mathrm{f}$ and $\mathrm{Cu} 2 \mathrm{p}$ spectra of Pt-skin bimetal-ceria, the Pt peaks obviously present but $\mathrm{Cu}$ peaks are not detected, distinguished from the bimetal-ceria specimen. The interesting observations were verified by repeating the measurements. XPS analyses indicated the outer layers (less than a few nm thick) of the specimen prepared by impregnation in twostep sequence, was predominantly $\mathrm{Pt}$, resulting in the Pt-skin structure. EDS analyses, capable to detect the elements to the depth of several micrometers, were further performed on the Pt-skin structured materials and confirmed the co-existence of $\mathrm{Cu}$ and $\mathrm{Pt}$ in the specimen. The average bulk composition of the $\mathrm{Cu}$ and $\mathrm{Pt}$ elements was 3.73 wt $\%$ and $0.98 \mathrm{wt} \%$, respectively. $\mathrm{Cu}$ and $\mathrm{Pt}$ are barely soluble in ceria and hence absorbed on the surface in ceria, which were manifested by XPS analyses. Further, cerium and oxygen composition in bare nano-ceria were quantized, with oxygen to cerium ratio in the range of 1.7 to 1.9 . The nonstoichiometry of the nano-ceria $\left(\mathrm{CeO}_{\mathrm{x}}\right)$ indicated more oxygen vacancy and higher electronic conductivity than $\mathrm{CeO}_{2}$, which will be beneficial to the reaction between hydrogen and oxygen ion on the anode side of SOFCs $(40-43)$. 

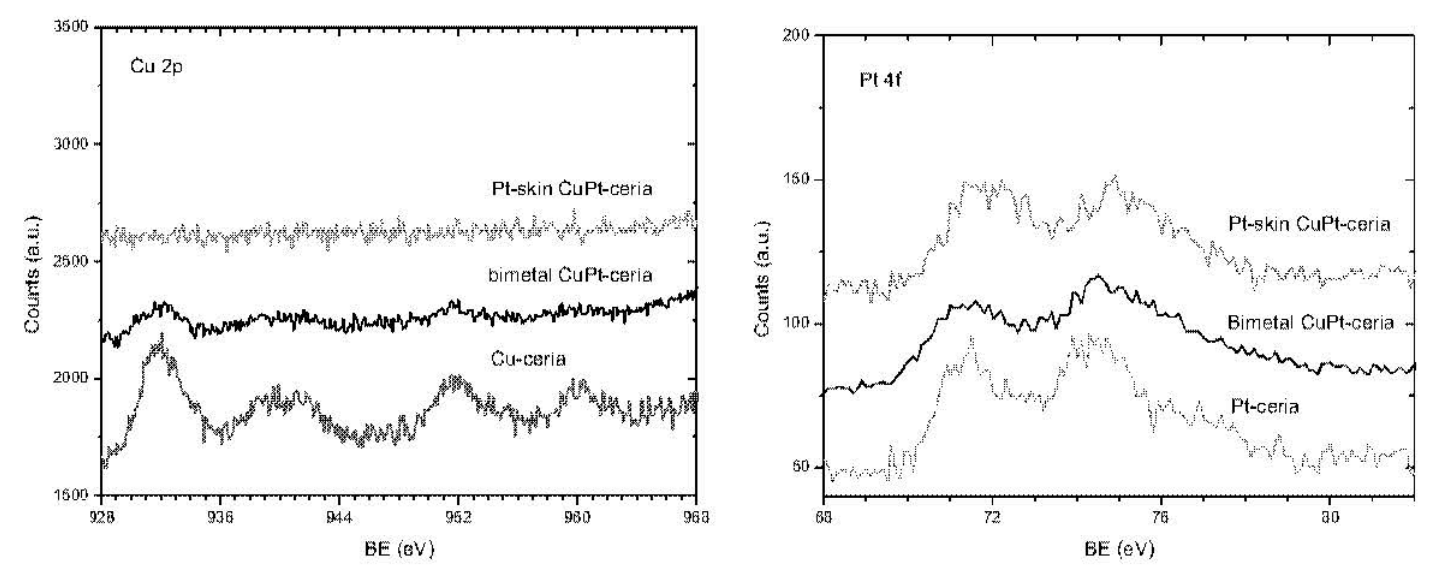

Figure 2. XPS fine-scan spectra of the catalyst specimens coated on nano-ceria in the binding energy ranges $\mathrm{Cu} 2 \mathrm{p}$ (left) and $\mathrm{Pt} 4 \mathrm{f}$ (right).

A portion of the $\mathrm{Cu}$-ceria specimen was subjected to reduction in a hydrogen atmosphere at $600^{\circ} \mathrm{C}$ to simulate the practical SOFC operating conditions. Figure 3 shows $\mathrm{Cu} 2 \mathrm{p}$ and $\mathrm{O} 1 \mathrm{~s}$ XPS spectra of the $\mathrm{Cu}$-ceria sample before and after reduction. The co-existence of $\mathrm{Cu} 2 \mathrm{p} 3 / 2$ and the typical $\mathrm{Cu} 2 \mathrm{p} 1 / 2$ shake-up satellites in the $\mathrm{Cu}$ coated ceria at $939.8 \mathrm{eV}$ and $960.0 \mathrm{eV}$, indicates the presence of $\mathrm{Cu}^{2+}$ ion in the oxide state. Additionally, the two well-splitted $\mathrm{O}$ 1s peaks located at $527.4 \mathrm{eV}$ and $529.3 \mathrm{eV}$ were associated with the oxygen bonding of $\mathrm{Ce}$ and $\mathrm{Cu}$, respectively. After the reduction process, the $\mathrm{Cu}$ satellite peaks as well as the $\mathrm{O} 1 \mathrm{~s}$ peak at $529.3 \mathrm{eV}$ decreased significantly, marked by the arrows in the figure. The results suggested copper in the as-prepared $\mathrm{Cu}-$ coated ceria existed in the oxidized state, but could be successfully reduced at the SOFC operational temperatures.
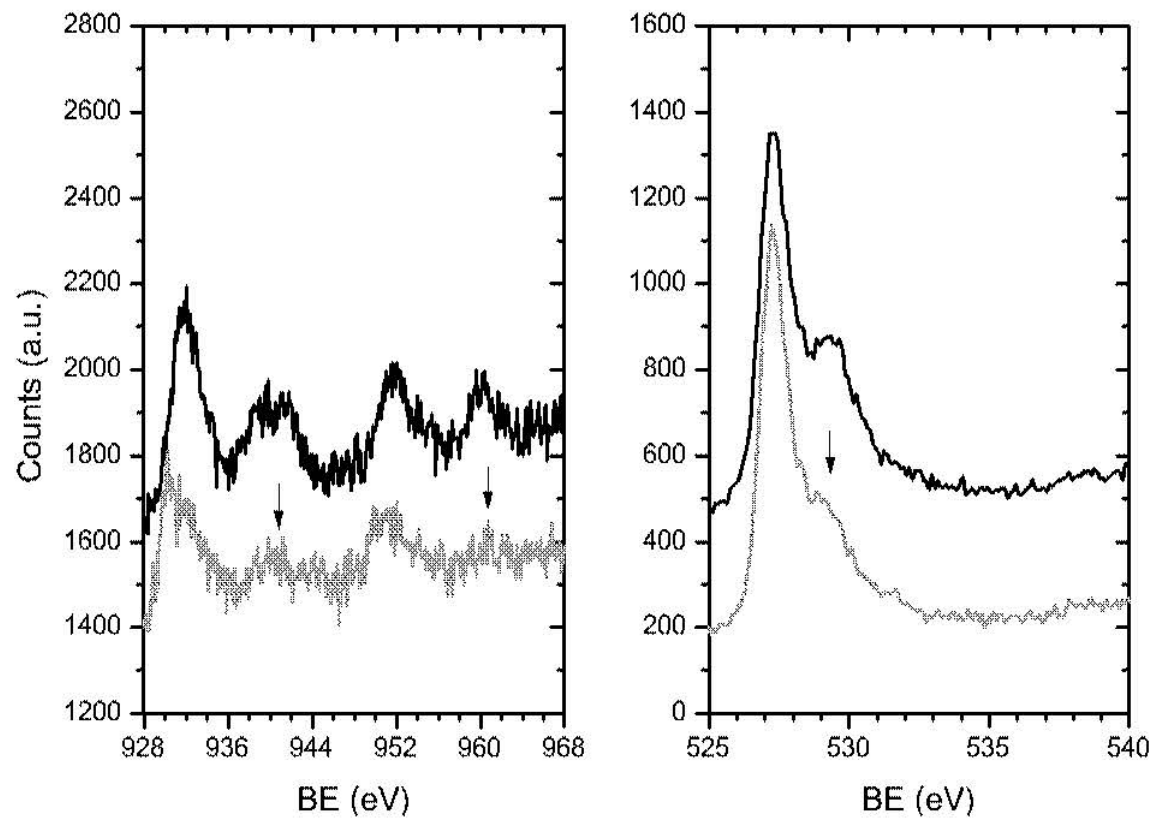

Figure 3. Comparison of XPS fine-scan spectra of the Cu-coated ceria specimen before (top profile) and after reduction (bottom profile) at $600^{\circ} \mathrm{C}$ in the binding energy ranges of $\mathrm{Cu} 2 \mathrm{p}$ (left) and $\mathrm{O} 1 \mathrm{~s}$ (right).

Figure 4 presents the XRD diffraction patterns of the two specimens, i.e. bimetal CuPt-ceria and Pt-skin CuPt-ceria, in comparison with the bare ceria specimen. In the 
spectrum of the bare ceria, all the diffraction peaks height and position were in agreement with Miller indices (111), (200), (220), (311), (222), (400), (331), and (420) and properly matched the corresponding values associated with the fluorite-structured cubic $\mathrm{CeO}_{2}(43)$. Interestingly, after the impregnation process, no visible peaks related to metallic $\mathrm{Cu}, \mathrm{Pt}$ or their oxide phases emerged. All the peak positions were further carefully examined and no significant position shifts occurred in comparison with bare nano-ceria. These observations implied that $\mathrm{Cu}$ and/or Pt may neither be present in the crystallographic structure nor be incorporated into the ceria structure. Alternatively, the observation may be the consequence of the low loading level of catalytic element, resulting by their Bragg peaks indistinguishable in the XRD pattern. The actual phase of the metallic catalyst will be subjected to further investigations by using transmission electron microscopy and electron diffraction in the future. The observed broadening peaks suggested smaller particle size of the bare ceria, which was further confirmed by AFM topographic imaging. The particle size of the Pt-skin CuPt-ceria, visualized from the AFM topographical image, is $63 \mathrm{~nm}$ in average (see figure 5). This value is slightly larger than that of uncoated ceria which has an average particle size of $60 \mathrm{~nm}$. Accordingly, the average catalyst particles are estimated about $3 \mathrm{~nm}$, vital to the catalytic efficiency.

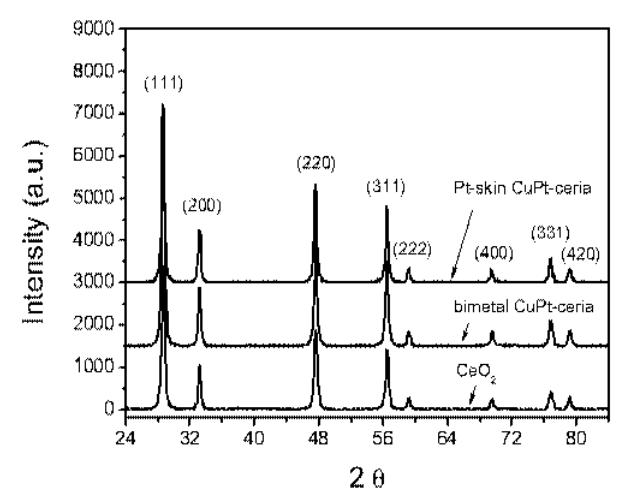

Figure 4. Diffraction spectra of the bare ceria, CuPt-ceria, Pt-skin CuPt-ceria.

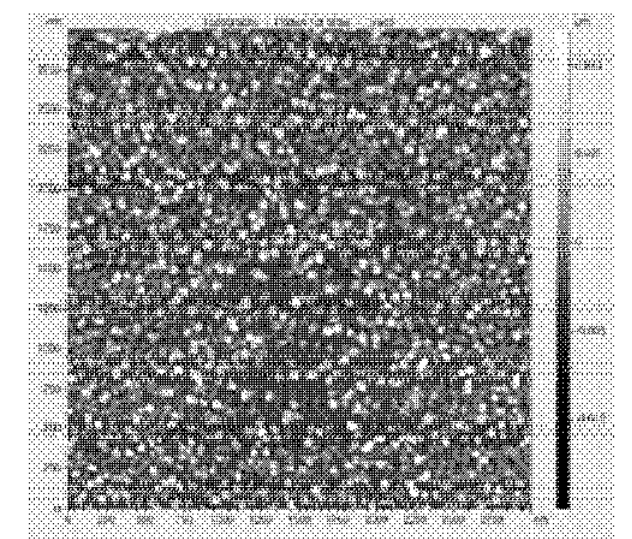

Figure 5. AFM image of the sol-gel synthesized Pt-skin CuPt-ceria .

In the previous report, impregnation of $\mathrm{Ni}$ to Pt supported on ceria exhibited better activity and tolerance in the presence of sulfur (44). Yoshimura et al. suggested that an increase of the electron-deficiency of noble metals could be essential to increase sulfur tolerance of noble metal catalysts (30). In effort to understand the surface sulfur interaction with the catalyst at a molecular level, Choi et al. analyzed sulfur tolerance of $\mathrm{Ni}, \mathrm{Cu}$, and $\mathrm{Ni}-\mathrm{Cu}$ alloys for SOFCs using computational ab initio method (45). It was subsequently concluded that $\mathrm{Cu}$ was more sulfur-tolerant than $\mathrm{Ni}$, and that alloying $\mathrm{Ni}$ with $\mathrm{Cu}$ improved sulfur tolerance. Recently, computational simulation was performed on four different compositional and nano-structured catalyst materials, i.e. pure $\mathrm{Cu}, \mathrm{Cu}-\mathrm{Pt}$ bimetal, Cu-skin structured Cu-Pt bimetal, and Pt-skin structured Cu-Pt bimetal. Preliminary results suggested that there was least interaction between the adsorbed sulfur atom and the Pt-skin structured $\mathrm{Cu}-\mathrm{Pt}$ bimetal catalyst, and hence the most sulfurresistant among the four candidates (46). It was further discovered that there existed significant charge transfer between $\mathrm{Cu}$ atoms and Pt atoms in the Pt-skin PtCu catalyst. The $\mathrm{Cu}$ atoms in the subsurface layer gained around 0.2 electron charge from the $\mathrm{Pt}$ atoms in the surface layer. The charge transfer from the $\mathrm{Pt}$ to $\mathrm{Cu}$ led to the electron

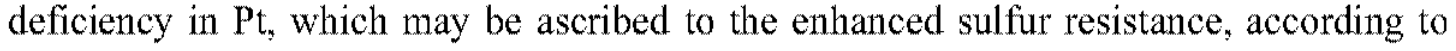


Yoshimura [30]. The Pt-skin structured CuPt bimetal catalyst supported on nanocrystalline ceria, reported in this paper, may be a promising anode alternative for SOFCs powered by sulfur-containing fuels. Performance assessments of SOFCs made up of the novel formula anode operating under various sulfur-containing conditions are in progress and will be reported in the conference.

\section{Conclusion}

$\mathrm{Cu}-\mathrm{Pt}$ bimetal and Pt-skin CuPt bimetal catalysts supported on nanocrystalline $\mathrm{CeO}_{2}$ were successfully achieved via the cost-effective synthesis combined sol-gel approach and impregnation process. The nano-ceria supporter had a fluorite structure, but $\mathrm{Cu}$ and Pt catalyst on top of the ceria probably exist in an amorphous phase on the surface. The average particle size of the Pt-skin catalyst coated ceria was $63 \mathrm{~nm}$ with the catalyst layer around $3 \mathrm{~nm}$. $\mathrm{Cu}$ components, present in an oxide state, can be easily reduced into a metallic state under fuel cell operating conditions. The Pt-skin CuPt-ceria may be a promising anode alternative for SOFCs powered by sulfur-containing fuels.

\section{Acknowledgments}

J. Bozeman and H. Huang would like to acknowledge the Ohio Space Grant Consortium for the financial support of this research. S. Mukhopadhyay acknowledges equipment support from Ohio Board of Regents and the National Science Foundation.

\section{References}

1. S. Satyapal, J. Petrovic, C. Read, G. Thomas, and G. Ordaz, Catalysis Today, 120, 246-256, (2007)

2. S.C. Singhal, Solid State Ionics, 135, 305-313, (2000)

3. S.M. Haile, Acta Materialia, 51, 5981-6000, (2003)

4. B.C.H. Steele and A. Heinzel, Nature, 414, 345-347, (2001)

5. B.P. Brandon, S. Skinner, and B.C.H. Steele, Annu. Rev. Mater. Res, 33, 183-196, (2003)

6. B.C.H. Steele, Nature, 400, 619-621, (1999)

7. A.L. Dicks, J. Power Sources, 61, 113-124, (1996)

8. E. Shoko, B. McLellan, A.L. Dicks and J.C. Diniz da Costa, Inter. J. Coal Geology, 65, 213-222, (2006)

9. M. Ormerod, Green Chem.-Roy. Soc. Chem., G61-G63, (2001)

10. M. Komiyama, T. Misonou, S. Takeuchi, K. Umetsu, and J. Takahashi, International Congress Series, 1293, 234-237, (2006)

11. B. Aldrich, S. Minott, and N. Scott, Manure management program report, (2005)

12. K. Cowey, K.J. Green, G.O. Mepsted, and R. Reeve, Solid State and Mater. Sci., $8367-371,(2004)$

13. I.C. Lee and H.C. Ubanyionwu, Fuel, 87, 312-318, (2008)

14. Y. Matsuzaki and I. Yasuda, Solid State Ionics, 132, 261-269, (2000)

15. K. Sasaki, K. Susuki, A. Iyoshi, M. Uchimura, N. Imamura, H. Kusaba, Y. Teraoka, H. Fuchino, K. Tsujimoto, Y. Uchida, and N. Jingo, J. Electrochem. Soc., 153, A2023-A2029, (2006) 
16. J.P. Trembly, A.I. Marquez, T.R. Ohrn, and D.J. Bayless, J. Power Sources, 158, 263-273, (2006)

17. L. Aguilar, S. Zha, Z. Cheng, J. Winnick, and M. Liu, J. Power Sources, 135, $17-$ 24, (2004)

18. F.P. Nagel, T.J. Schildhauer, J. Sfeir, A. Schuler, and S.M.A. Biollaz, J. Power Sources, 189, 1127-1131, (2009)

19. Z.F. Zhou, C. Gallo, M.B. Pague, H. Schobert, and S.N. Lvov, J. Power Sources, 133, 181-187, (2004)

20. T.R. Smith, A. Wood, and V.I. Birss, Applied Catalysis A: General, 354, 1-7, (2009)

21. M. Liu, P. He, J.L. Luo, A.R. Sanger, and K.T. Chuang, J. Power Sources, 94 , 20-25, (2001)

22. S. Wang, M. Liu, and J. Winnick, J. Solid State Electrochem., 5, 188-195, (2001)

23. A. Atkinson, S. Barnett, R.J. Gorte, J.T.S. Irvine, A.J. McEvoy, M. Mogensen, S.C. Singhal and J. Vohs, Nature Materials, 3, 17-27, (2004)

24. D. Weaver and J. Winnick, J. Electrochem. Soc., 136, 1679-1686, (1989)

25. Y.M. Choi, C. Compson, M.C. Lin, and M. Liu, Chem. Phys. Lett., 421, 179-183, (2006)

26. J. Dong, Z. Cheng, S. Zha, and M. Liu, J. Power Sources, 156, 461-465, (2006)

27. H. Kurokawa, L. Yang, C.P. Jacobson, L.C. De Jonghe, and S.J. Visco, J. Power Sources, 164, 510-518, (2007)

28. H. Kim, J.M. Vohs, and R.J. Gorte, Chem. Commun., 22, 2334-2335, (2001)

29. M. Gong, X. Liu, J. Trembly and C. Johnson, J. Power Sources, 168, 289-298, (2007)

30. Y. Yoshimura, M. Toba, T. Matsui, M. Harada, Y. Ichihashi, K.K. Bando, H. Yasuda, H. Ishihara, Y. Morita, and T. Kameoka, Appl. Catalysis A, 322, 152-171, (2007)

31. H. He, R. Gorte, and J. Vohs, Electrochem. \& Solid-State Lett., 8, A279-A280, (2005)

32. H. Devianto, S.P. Yoon, S.W. Nam, J. Han, and T. Lim, J. Power Sources, 159, $1147-1152,(2006)$

33. R. Gorte, H. Kim, and J. Vohs, J. Power Sources, 106, 10-15, (2002)

34. A. Azad, M.J. Duran, A. McCoy, and M. Abraham, Appl. Catalysis A: General, 332, 225-236, (2007)

35. V.P. Pakharukova, E.M. Moroz, V.V. Kriventsov, D.A. Zyuzin, G.R. Kosmambetova, and P.E. Strizhak, Appl. Catalysis A, 365, 159-164, (2009)

36. H.P. He, A. Wood, D. Steedman, and M. Tilleman, Solid State Ionics, 179, 1478$1482,(2008)$

37. Z. Zhan and S. A. Barnett, Science, 308, 844, (2005)

38. D. Brandon and W.D. Kaplan, Microstrucutral Characterization of Materials, $2^{\text {nd }}$ edition, John Wiley \& Sons, (2007)

39. J.B. Wachtman, Characterizations of Materials, Buttersworth-Heinemann, (1993)

40. T. Suzuki, I. Kosacki, and H.U. Anderson, J. Am. Ceram. Soc., 85, 1492, (2002)

41. H. Huang, T. Holme, and F.B. Prinz, J. Fuel Cell Sci. \& Tech., 7, 041012, (2010)

42. E. Ruiz-Trejo, J.D. Sirman, Yu. M. Baikov, and J.A. Kilner, Solid State Ionics, 113-115, 565-569, (1998)

43. M. Mogensen, N. Sammes, and G. Tompsett, Solid State Ionics, 129, 63-94, (2000) 
44. H. Kurokawa, T.Z. Sholklapper, C.P. Jacobson, L.C. De Jonghe, and S.J. Visco, Electrochem. Solid-State Lett., 10, B135-B138, (2007).

45. Y. Choi, C. Compson, M. Lin, and M. Liu, J. Alloys \& Comp., 427, 25-29, (2007)

46. J. F. Bozeman III, Sulfur-Tolerant Catalyst for the Solid Oxide Fuel Cells, OhioLINK Electronic Thesis and Dissertation Center, (2010). 